\title{
Sampling description and procedures used to conduct the North/South Ireland Food Consumption Survey
}

\author{
M Kiely ${ }^{1, *}$, A Flynn ${ }^{1}$, KE Harrington ${ }^{2}$, PJ Robson ${ }^{3}$ and G Cran ${ }^{4}$ \\ Irish Universities Nutrition Alliance (IUNA) at: 'Nutritional Sciences, Department of Food Science, \\ Food Technology and Nutrition, University College, Cork, Republic of Ireland: \\ ${ }^{2}$ Department of Clinical Medicine, Trinity Centre for Health Sciences, St. James's Hospital, Dublin 8 , \\ Republic of Ireland: ${ }^{3}$ Northern Ireland Centre for Diet and Health (NICHE), University of Ulster, Coleraine, \\ Co. Londonderry, BT52 1SA, Northern Ireland: ${ }^{4}$ Department of Epidemiology and Public Health, Queens University, \\ Belfast BT9 5EE, Northern Ireland
}

\begin{abstract}
Objective: The purpose of this survey was to establish a database of habitual food and drink consumption in a representative sample of Irish adults, aged 18-64 years. The present paper describes the sampling protocol, response rate and characteristics of the survey population in terms of sex and age groups, seasonality, geographical location, marital status, social class, socio-economic status and education level. Design: A cross-sectional food consumption survey was carried out. In the Republic of Ireland, a nationally representative sample of adults was randomly selected with a validated two-stage clustered design, using the electoral register as the sampling frame. This method produced a self-weighting or 'epsem' sample of individuals, where each adult who was registered to vote had an equal opportunity of being selected. Similarly, in Northern Ireland, a two-stage random sampling procedure was used. The sampling frame was the electoral register, and the sample was stratified by urban/rural and by an index of material deprivation, to ensure representation of each sector of the community. The recruitment procedure was the same in the North and South. An introductory letter with an information leaflet was posted to each selected individual and these were followed up by a visit from a fieldworker, who invited participation in the survey.

Setting: Northern Ireland and Republic of Ireland between 1997 and 1999.

Results: The response rate, which is the percentage of the total number of people who completed a 7-day food diary $(n=1379)$ out of the total eligible sample $(n=2177)$, was $63 \%$. Non-respondents and dropouts constituted $34 \%$ and $3 \%$, respectively, of the total eligible sample. Compared with the most recent census figures available, the sample was generally found to be representative in terms of sex and age group profiles, geographical location, marital status, seasonality, social class, socio-economic group and education level. Data on sex and age group and geographical location were collected from non-respondents for comparison with the survey sample. There were no apparent differences between them.

Conclusion: The North/South Ireland Food Consumption Survey has established a relational database of habitual food and drink consumption, in addition to data on habitual physical activity, anthropometric measurements, socio-demographic factors, lifestyle, health status indicators and attitudes, in a nationally representative sample of the population of the island of Ireland.
\end{abstract}

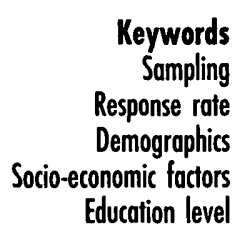

Food consumption surveys are established in most countries of the developed world to monitor trends in food and nutrient consumption. The data are used for many purposes, including the assessment of inadequate or excessive nutrient intakes, and the estimation of exposure to food chemicals and additives. The results produced by food consumption surveys can often highlight underlying nutritional problems in the population and can prompt governments to carry out more detailed studies to investigate causes and recommend solutions.

Cardiovascular disease (CVD) is the major cause of 
death in the Republic of Ireland $(41 \%)^{1}$ and Northern Ireland $(43 \%)^{2}$. The World Health Organization (WHO) ${ }^{3}$ has highlighted the importance of research into several risk factors for CVD including nutrition, physical inactivity, insulin resistance, overweight and excessive alcohol consumption. In addition to collecting individual habitual food consumption data for the measurement of nutrient and food chemical intakes, the current survey established a relational database containing individual habitual physical activity levels, anthropometric measurements (including weight, height, waist and hip circumference and percentage body fat), smoking habits, alcohol consumption and socio-economic factors (including education level). A highly trained team used standardised procedures to collect these data.

The current survey was unique, because it was the first project of its kind to be undertaken in the North and South of Ireland using the same methodology. This paper outlines the sampling protocol and the recruitment procedure used in the survey. The response rate is described in relation to the completion of the 7-day food diary, which was the condition that defined response/ non-response, although there were other important components to the project. Characteristics of the survey population are described in terms of sex and age groups, geographical location, marital status, social class and socio-economic status, and education level. Where possible, these variables are compared with the most recent available population statistics to determine the extent to which the survey sample was representative of the population as a whole. Data were also collected for non-respondents, including sex and age group and geographical location, for comparison with the responding sample.

\section{Methods}

\section{Sampling procedure}

In the Republic of Ireland, a sample of adults (aged at least 18 years on 15th February 1997) was randomly selected using a validated computerised random selection system called RANSAM ${ }^{4}$, which implements a two-stage clustered design using the electoral register as the sampling frame. The electoral register consists of roughly 5500 polling books. Each book is divided into District Electoral Divisions (DEDs). The first stage of the sampling process involves the selection of clusters of DEDs or polling districts, which are the Primary Sampling Units (PSUs). Thus, the first stage of sampling provided a sample of PSUs, stratified by region, with a selection probability proportional to size. The second stage of sampling involved the selection of electors from within the PSUs. RANSAM produces a self-weighting or 'epsem' sample of individuals. The use of the electoral register as the framework for sampling has some disadvantages, the most important of which is non-registration. The nonregistered group makes up about $0.5 \%$ of the population who should be on the electoral register, and is a transient group consisting mainly of 18-20 year olds and elderly people.

In Northern Ireland, a two-stage sampling procedure incorporating two elements of stratification was used. The PSUs were the 582 electoral wards listed in the 1997-1999 Register of Electors for Northern Ireland, stratified into urban and rural wards. For the purposes of this study, wards in the Local Government Districts of Belfast, Castlereagh, North Down, Carrickfergus, Newtownabbey, Lisburn, Ards (excluding the District Electoral Areas (DEAs) of Ards Peninsula and Ards West) and Londonderry (excluding Derry Rural) were designated as urban wards. Wards in the remaining 18 Local Government Districts and the DEAs of Ards Peninsula, Ards West and Derry Rural were designated as rural wards. In the second stratification, each electoral ward was assigned to one of five classes (designated T1 to T5) based on the Townsend Index of Material Deprivation Scores. This is an ordinal classification, T1 being the least deprived to $\mathrm{T} 5$ being the most deprived. The scores for each ward were calculated using census data ${ }^{5}$. Based on the distribution of the population, 17 wards were selected. The probability of a ward being selected was proportional to its size. For each selected ward, a number of subjects were randomly selected from the electoral list for possible inclusion in the survey. In order to achieve the target sample size, a quota system was employed, meaning that fieldworkers stayed in each ward until their target numbers for that ward in that season were achieved. Each selected ward was visited twice, once in the winter season and once in the summer season.

\section{Exclusion criteria}

Adults between the ages of 18 and 64 years were eligible for inclusion in the survey. It was decided that the use of a 7-day food diary, which places a considerable burden on the respondent, precluded the inclusion of elderly people, and it is hoped that a food consumption survey will be carried out in the elderly population in the near future. Otherwise, there were few exclusion criteria. Pregnant and lactating women were excluded because their nutritional requirements are different from those of women who are not pregnant. The overall energy cost of pregnancy has been estimated at $303 \pm 171 \mathrm{MJ}$, which is largely met by an increase in energy intake over the last two trimesters ${ }^{6}$. The expansion of blood volume and the growth of foetal and maternal tissues place an extra protein demand on the pregnant woman, which has been estimated at $900 \mathrm{~g}$ in total. Using population statistics from Census ' $96^{7}$, combined with the 1995 birth rate, it was estimated that at least $5 \%$ of the women who participated in the survey were likely to be pregnant. This number of 
pregnant women would have been too large to include in the total sample, and too small to study as a separate group.

The presence of a learning disability did not automatically exclude a person from participating in the survey, provided there was a carer who would ensure that the 7-day food diary was accurate and complete.

\section{Sample recruitment}

An introductory letter plus an information leaflet were posted to each person who was selected in a cluster one week before that cluster was targeted by a researcher. The researcher called to each potential respondent's home to introduce the survey and invite participation. If the person agreed to participate, a consent form was signed and the study protocol commenced, described in an accompanying paper ${ }^{8}$. If the person was not at home, the researcher left a note including a card with name and contact number. The researcher called three more times to the person's home at different times. If the person declined to participate in the survey, the researcher attempted to obtain information such as age, education and occupation, in order to describe non-respondents.

\section{Results and discussion}

\section{Response to the survey}

Completion of the 7-day food diary was the criterion used to distinguish respondents from non-respondents and dropouts. The response rate to the survey is described in Table 1. As the sample was selected from the electoral register, the names and addresses of the potential respondents were the only details available. Therefore, the ineligible sample, which accounted for $60 \%$ of the total sample selected, contained people who were excluded, due to being over 64 years old, deceased, pregnant or breast-feeding, and people who were noncontactable due to being away, having an invalid address, being institutionalised or on holiday. The final response rate $(63 \%)$ was calculated from the number of respondents who completed a 7-day food diary $(n=1379)$ out of the total eligible sample $(n=2177)$. Non-respondents and dropouts constituted $34 \%$ and $3 \%$, respectively, of the

Table 1 Response rate of the survey sample

\begin{tabular}{lrrr}
\hline & All & Men & Women \\
\hline Total number selected & 5469 & 2731 & 2738 \\
Total ineligible sample & 3292 & 1663 & 1629 \\
Excluded & 1467 & 690 & 777 \\
Non-contactable & 1825 & 977 & 848 \\
Total eligible sample & 2177 & 1068 & 1109 \\
Non-responders & 739 & 377 & 362 \\
Dropouts & 59 & 29 & 30 \\
Responders & 1379 & 662 & 717 \\
Final response rate* & $63 \%$ & $62 \%$ & $65 \%$ \\
\hline
\end{tabular}

* \% of the eligible sample who completed a 7-day food diary. total eligible sample. Information about non-respondents was recorded, including sex, age group, season and geographical location, for comparison with the survey sample.

\section{Characteristics of the survey sample}

\section{Sex and age}

The numbers of respondents in each sex and age group are shown in Table $2 \mathrm{a}$. Thirty eight per cent of men and women were in the 18-35 year age group, $36 \%$ of men and $40 \%$ of women were in the $36-50$ year age group, and $26 \%$ of men and $22 \%$ of women were in the $51-64$ year age group. According to Census ' $96^{7}, 46 \%$ of men and women in the Republic are aged between 18 and 35 years, $33 \%$ are between 36 and 50 years, and 20\% are between 51 and 64 years. The last Census carried out in Northern Ireland, in $1991^{5}$, found that $47 \%$ of men and $46 \%$ of women were between 18 and 35 years, $30 \%$ of men and women were between 36 and 50 years, and $22 \%$ of men and $24 \%$ of women were between 51 and 64 years. The age profile of the current survey shows a slight under-representation of the 18-35 year age group and a slight over-representation of the 36-50 year age group compared with these census figures. In Table $2 b$ the numbers and percentages of non-respondents in each age and sex group are presented for comparison with respondents. The data show that only $25 \%$ of male and $31 \%$ of female non-respondents were in the 18-35 year group, suggesting that non-response was not the reason why this age group was slightly under-represented in the survey sample. When participation in the survey was invited, a higher proportion of 18 to 35 year olds were not contactable compared with older adults, as they were studying, working away from home or travelling abroad.

The numbers of respondents in each sex and age subgroup of the population are sufficient to facilitate statistical analysis of food and nutrient intakes and health status indicators.

\section{Seasonality}

Table 3 a shows the numbers and percentages of men and

Table 2 Numbers of respondents and non-respondents (\%) in each sex and age group*

\begin{tabular}{lcccc}
\hline & All & 18-35 years & 36-50 years & 51-64 years \\
\hline (a) Respondents & & & \\
Men & 662 & $253(38)$ & $236(36)$ & $173(26)$ \\
Women & 717 & $269(38)$ & $286(40)$ & $162(22)$ \\
$n$ & 1379 & 522 & 522 & 335 \\
(b) Non-respondents & & & \\
Men & 377 & $95(25)$ & $159(42)$ & $104(28)$ \\
Women & 362 & $114(31)$ & $135(37)$ & $104(29)$ \\
$n$ & 739 & 209 & 294 & 208 \\
\hline
\end{tabular}

\footnotetext{
* Age group not known for 19 men (5\%) and nine women (3\%).
} 
Table 3 Numbers of respondents and non-respondents (\%) to the survey during winter (Sept-Feb) and summer (Mar-Aug)

\begin{tabular}{lll}
\hline & Men & Women \\
\hline (a) Respondents & $367(55)$ & \\
Winter & $295(45)$ & $370(52)$ \\
Summer & 662 & $347(48)$ \\
$n$ & & 717 \\
(b) Non-respondents & $199(53)$ & \\
Winter & $178(47)$ & $188(52)$ \\
Summer & 377 & $174(48)$ \\
$n$ & & 362 \\
\hline
\end{tabular}

women who participated in the survey during the winter and summer seasons between 1997 and 1999, when the fieldwork was carried out. Slightly higher numbers of respondents participated in the survey during the winter months. There were no major differences between the percentages of respondents and non-respondents in winter and summer (Table 3b).

\section{Geographical location}

Table 4a describes the numbers and percentages of respondents living in urban and rural areas by sex and age group. Thirty eight per cent of men and $34 \%$ of women lived in the open country or a village of less than 1499 inhabitants. Eleven per cent of men and women lived in a small town of between 1500 and 9999 inhabitants and $17 \%$ of men and women lived in a large town with a population of over 10000 . Thirty four per cent of men and $38 \%$ of women lived in cities, including Dublin, Cork, Belfast, Limerick, Galway, Derry and Waterford. These values correspond closely with those of Census ' $96^{7}$, which showed that $32 \%$ of the population lives in rural areas and villages of less than 1499 people, $11.4 \%$ live in small towns and more than $10 \%$ live in large towns with a population of over 10000 . The proportion of the population of the South that was resident in the five major cities (Dublin, Cork, Limerick, Galway and Waterford) was 36.3\%. These classifications of geographical location were not available for comparison in the Northern Ireland Census $1991^{5}$. Table $4 \mathrm{~b}$ describes the numbers and percentages of non-respondents living in urban and rural areas by sex and age group. There were no substantial differences between the proportions of respondents and non-respondents in the separate geographical locations.

\section{Marital status}

Table 5 describes the marital status of respondents by sex and age group. Sixty seven per cent of men and $68 \%$ of women were married or living with a partner, $30 \%$ of men and $24 \%$ of women were single, and a small number of people (19 men and 51 women) classified themselves as widowed, separated or divorced. According to Census ' $967,36 \%$ of the population in the South aged 20 to 64 years are single and $62 \%$ are married. Similarly, $36 \%$ of men and women aged 18 to 64 years were single and $62 \%$ were married in the Northern Ireland Census $1991^{5}$. In the current survey, a slightly smaller percentage of people

Table 4 Geographical location of respondents and non-respondents (\%) by sex and age group*

\begin{tabular}{|c|c|c|c|c|}
\hline & All & $18-35$ years & $36-50$ years & $51-64$ years \\
\hline \multicolumn{5}{|l|}{ (a) Respondents } \\
\hline Open country/village & $251(38)$ & $82(33)$ & $92(39)$ & $77(44)$ \\
\hline Small town & $76(11)$ & $34(13)$ & $22(9)$ & $20(12)$ \\
\hline Large town & 111 (17) & $45(18)$ & $40(17)$ & $26(15)$ \\
\hline City & $224(34)$ & $92(36)$ & $82(35)$ & $50(29)$ \\
\hline$n$ & $662(100 \%)$ & $253(100 \%)$ & $236(100 \%)$ & $173(100 \%)$ \\
\hline \multicolumn{5}{|l|}{ Women } \\
\hline Open country/village & $245(34)$ & $72(27)$ & $101(35)$ & $72(44)$ \\
\hline Small town & $81(11)$ & $40(15)$ & $28(10)$ & $13(8)$ \\
\hline Large town & 119 (17) & 49 (18) & $51(18)$ & $19(12)$ \\
\hline City & $272(38)$ & $108(40)$ & $106(37)$ & $58(36)$ \\
\hline$n$ & $717(100 \%)$ & $269(100 \%)$ & $286(100 \%)$ & $162(100 \%)$ \\
\hline \multirow{2}{*}{\multicolumn{5}{|c|}{$\begin{array}{l}\text { (b) Non-respondents } \\
\text { Men }\end{array}$}} \\
\hline & & & & \\
\hline Open country/village & $149(39)$ & $35(37)$ & $60(38)$ & $46(44)$ \\
\hline Small town & $40(11)$ & $9(9)$ & $23(14)$ & $6(6)$ \\
\hline Large town & $68(18)$ & $21(22)$ & $30(19)$ & $16(15)$ \\
\hline City & $120(32)$ & $30(32)$ & $46(29)$ & $36(35)$ \\
\hline$n$ & $377(100 \%)$ & $95(100 \%)$ & $159(100 \%)$ & $104(100 \%)$ \\
\hline \multicolumn{5}{|l|}{ Women } \\
\hline Open country/village & $121(33)$ & $39(34)$ & $37(27)$ & $42(40)$ \\
\hline Small town & 46 (13) & $13(11)$ & $23(17)$ & $10(10)$ \\
\hline Large town & 67 (19) & $19(17)$ & $25(19)$ & $21(20)$ \\
\hline City & $128(35)$ & $43(38)$ & $50(37)$ & $31(30)$ \\
\hline$n$ & $362(100 \%)$ & $114(100 \%)$ & $135(100 \%)$ & $104(100 \%)$ \\
\hline
\end{tabular}

* Age group not known for 19 men (5\%) and nine women (3\%). 
Table 5 Marital status of respondents by sex and age group

\begin{tabular}{|c|c|c|c|c|c|c|c|c|}
\hline \multirow[b]{2}{*}{ Marital status } & \multicolumn{4}{|c|}{ Men } & \multicolumn{4}{|c|}{ Women } \\
\hline & All & $\begin{array}{l}18-35 \\
\text { years }\end{array}$ & $\begin{array}{l}36-50 \\
\text { years }\end{array}$ & $\begin{array}{l}51-64 \\
\text { years }\end{array}$ & All & $\begin{array}{l}18-35 \\
\text { years }\end{array}$ & $\begin{array}{l}36-50 \\
\text { years }\end{array}$ & $\begin{array}{l}51-64 \\
\text { years }\end{array}$ \\
\hline$n^{\star}$ & 660 & 252 & 235 & 173 & 713 & 269 & 285 & 159 \\
\hline Single $(\%)$ & $199(30)$ & $157(62)$ & $27(11)$ & $15(15)$ & $175(24)$ & $140(52)$ & $24(8)$ & $11(7)$ \\
\hline Married or living with partner (\%) & $442(67)$ & $94(27)$ & $200(85)$ & $148(86)$ & $487(68)$ & $120(45)$ & $244(85)$ & $123(76)$ \\
\hline Widowed & 4 & 0 & 1 & 3 & 25 & 0 & 7 & 18 \\
\hline Separated & 10 & 1 & 5 & 4 & 16 & 5 & 7 & 4 \\
\hline Divorced & 5 & 0 & 2 & 3 & 10 & 4 & 3 & 3 \\
\hline
\end{tabular}

"Excludes six missing values.

were classified as single compared with the census figures and this is because people who were living with a partner were included in the same category as those who were married.

\section{Social class and socio-economic group}

Respondents were classified according to social class and socio-economic group, using the Irish and UK classification systems ${ }^{9-12}$. Tables $6 \mathrm{a}$ and $6 \mathrm{~b}$ show the numbers and percentages of men and women in the Irish and UK social class categories. Tables $7 \mathrm{a}$ and $7 \mathrm{~b}$ show the numbers and percentages of men and women in the Irish and UK socioeconomic group categories. The percentages of men and women in each category were similar for both the Irish and the UK social class and socio-economic group classifications, with the exception that there were more women in the non-manual categories than men and more men in the skilled manual categories than women. A comparison with the social class data from Census ' $96^{13}$ showed that, for men, the percentages in each social class category in the current survey were very similar to the census data for 25 to 64 year olds. However, a smaller

Table 6 Social class of respondents (\%) by sex

\begin{tabular}{lcc}
\hline & Men & Women \\
\hline (a) Social class (Ire) & $61(9)$ & $71(10)$ \\
Professional Workers & $207(32)$ & $232(34)$ \\
Managerial and Technical & $91(14)$ & $162(24)$ \\
Non-manual & $155(24)$ & $106(15)$ \\
Skilled Manual & $81(13)$ & $87(13)$ \\
Semi-skilled Manual & $31(5)$ & $17(2)$ \\
Unskilled Manual & $20(3)$ & $14(2)$ \\
Students & 646 & 689 \\
$n^{*}$ & & \\
(b) Social class (UK) & $51(8)$ & $57(8)$ \\
Professional Occupations & $230(36)$ & $249(36)$ \\
Managerial and Technical Occupations & $76(12)$ & $156(23)$ \\
Non-manual (skilled) & $161(25)$ & $104(15)$ \\
Manual (skilled) & $84(13)$ & $82(12)$ \\
Partly Skilled Occupations & $22(3)$ & $24(3)$ \\
Unskilled Occupations & $20(3)$ & $16(2)$ \\
Students & 644 & 688 \\
$n \dagger$ & & \\
nt & &
\end{tabular}

* Excludes 44 missing values.

† Excludes 47 missing values. percentage of women were in professional (5\%) and managerial and technical (25\%) categories in Census ' $96^{13}$ compared with the current study $(10 \%$ and $34 \%$, respectively). This trend was not present to the same extent when the socio-economic data were compared. Recent data on social class and socio-economic groups from Northern Ireland were not available for comparison with the survey.

The data show that the survey sample was representative of the total population (of the South) in terms of the percentages in each social class and socio-economic group category. The minor differences in the percentages of women in the first two social class categories may be due to the slightly different data collection and coding methods used in the survey and in the census. Data were collected for the survey on an individual basis; each respondent completed the questionnaire for him/herself only, whereas in Census ' $96^{13}$, one of the joint heads of household completed the questionnaire for everyone in

Table 7 Socio-economic group of respondents (\%) by sex

\begin{tabular}{lcc}
\hline & Men & Women \\
\hline (a) Socio-economic group (Ire) & $108(17)$ & $89(13)$ \\
Employers and Managers & $56(9)$ & $62(9)$ \\
Higher Professional & $86(13)$ & $120(18)$ \\
Lower Professional & $84(13)$ & $192(28)$ \\
Non-manual & $108(17)$ & $61(9)$ \\
Manual Skilled & $68(11)$ & $59(9)$ \\
Semi-skilled & $28(4)$ & $23(3)$ \\
Unskilled & $30(5)$ & $24(3)$ \\
Own Account Workers & $49(7)$ & $42(6)$ \\
Farmers & $9(1)$ & $1(<1)$ \\
Agricultural Workers & $21(3)$ & $15(2)$ \\
Students & 647 & 688 \\
$n^{*}$ & & \\
(b) Socio-economic group (UK) & $49(8)$ & $56(8)$ \\
Professional & $143(22)$ & $107(15)$ \\
Employers and Managers & $151(23)$ & $269(39)$ \\
Other Non-manual Workers & $178(27)$ & $130(19)$ \\
Skilled Manual Workers & $80(12)$ & $88(13)$ \\
Semi-skilled Manual & $25(4)$ & $25(4)$ \\
Unskilled Manual & $2(<1)$ & $2(<1)$ \\
Members of Armed Forces & $20(3)$ & $13(2)$ \\
Students & 648 & 690 \\
$n \dagger$ & & \\
n† & & \\
\hline "Excludes 44 missing values. & & \\
$\dagger$ Excludes 41 missing values. & &
\end{tabular}


Table 8 Education level of respondents (\%) by sex and age group

\begin{tabular}{llccc}
\hline & All & $\begin{array}{c}18-35 \\
\text { years }\end{array}$ & $\begin{array}{c}36-50 \\
\text { years }\end{array}$ & $\begin{array}{c}51-64 \\
\text { years }\end{array}$ \\
\hline Men & $140(22)$ & $21(8)$ & $49(21)$ & $70(43)$ \\
$\quad$ Primary & $128(20)$ & $51(20)$ & $54(23)$ & $23(14)$ \\
Intermediate & $113(17)$ & $55(22)$ & $36(15)$ & $22(14)$ \\
Secondary & $266(41)$ & $124(49)$ & $94(40)$ & $48(29)$ \\
Tertiary & $647(100 \%)$ & $251(100 \%)$ & $233(100 \%)$ & $163(100 \%)$ \\
$n^{*}$ & & & & \\
Women & $149(21)$ & $22(8)$ & $49(18)$ & $78(50)$ \\
Primary & $154(22)$ & $61(23)$ & $70(25)$ & $23(15)$ \\
Intermediate & $142(20)$ & $52(19)$ & $68(24)$ & $22(14)$ \\
Secondary & $257(37)$ & $132(49)$ & $93(33)$ & $32(21)$ \\
Tertiary & $702(100 \%)$ & $267(100 \%)$ & $280(100 \%)$ & $155(100 \%)$ \\
$n^{*}$ & & &
\end{tabular}

* Excludes 30 missing values.

the household. In the survey, when a respondent and his/her partner were gainfully employed, data on employment status were collected for both partners and the higher social class category of the two was assigned to the respondent. This may have resulted in reclassification for a proportion of women in gainful employment whose partner's social class category was higher than their own. In Census ' $96^{13}$, each person who was gainfully employed was assigned a social class category to him/herself, meaning that persons living in a family household may be placed in different social class categories.

\section{Education level}

Table 8 shows numbers and percentages of men and women in different age groups according to education level. The levels are 'primary' (includes people who have no formal secondary school education), 'intermediate' (includes people who have some secondary school education but do not hold a school leaving or A-level certificate), 'secondary' (includes people who have a secondary school leaving or A-level certificate) and 'tertiary' (includes people who went to university or college). For all ages, there were similar percentages of men and women in the different levels of education. There was a very clear trend showing higher percentages of people in the tertiary level and lower percentages in the primary level as the age of the group decreased.

In Census ' $96^{7}$, among people aged 15 years and above, there were roughly similar percentages in the primary (29\%), intermediate (21\%) and secondary levels (29\%) compared with the survey. However, the survey population contained a higher proportion of people with tertiary education compared with the census (19\%). This was due to two reasons; the census population includes people over 65 years old, of whom a smaller percentage have tertiary education, and the survey coding system included a broader range of qualifications, including technical college and city and guilds qualifications, in the tertiary category. In the Northern Ireland Census $1991^{5}$, among people aged 18 to 64 years, the percentage of men and women at intermediate level (20\%) was similar to the survey and to Census ' 96 , but the percentages at primary (60\%), secondary (9\%) and tertiary (10\%) level were different from the survey and Census ' 96.

\section{Conclusions}

In conclusion, the North/South Ireland Food Consumption Survey has established a relational database of habitual food and drink consumption in a nationally representative sample of the population of the island of Ireland. This database also contains information on habitual physical activity, anthropometric measurements, socio-demographic factors, lifestyle, health status indicators and attitudes. It is therefore valid to extrapolate conclusions drawn from the analysis of this database to the population as a whole.

\section{References}

1 Central Statistics Office. Vital Statistics 4tb Quarter and Yearly Summary 1999. Dublin: Central Statistics Office, 2000.

2 British Heart Foundation. Coronary Heart Disease Statistics. British Heart Foundation Statistics 1999. London: British Heart Foundation, 1999.

3 WHO. Cardiovascular Disease Risk Factors: New Areas for Research. Technical Report Series 841. Geneva: World Health Organization, 1994.

4 Whelan BJ. Ransam: a random sample design for Ireland. Econ. Social Rev. 1979; 10: 169-74.

5 Department of Health and Social Services Registrar General Northern Ireland. The Northern Ireland Census 1991. Belfast: HMSO, 1992.

6 Piers LS, Diggavi SN, Thangam S, van Raaj JM, Shetty PS, Hautvast JG. Changes in energy expenditure, anthropometry and energy intake during the course of pregnancy and lactation in well-nourished Indian women. Am. J. Clin. Nutr. 1995; 61: 501-13.

7 Central Statistics Office. Census '96 Principal Demographic Results. Dublin: Government of Ireland, 1997.

8 Harrington $\mathrm{KE}$, Robson PJ, Kiely M, Livingstone MBE, Lambe J, Gibney MJ. The North/South Ireland Food 
Consumption Survey: survey design and methodology. Public Health Nutr. 2001; 4(5A): 1037-42.

9 Office of Population Census and Surveys. Standard Occupational Classification. Volume 1. Structure and Definition of Major, Minor and Unit Groups. London: HMSO, 1990.

10 Office of Population Census and Surveys. Standard Occupational Classification. Volume 2. London: HMSO, 1995.
11 Office of Population Census and Surveys. Standard Occupational Classification. Volume 3. Social Classifications and Coding Methodology. London: HMSO, 1991.

12 Central Statistics Office. Census 1996. Volume 7. Occupations. Dublin: Central Statistics Office, 1998.

13 Central Statistics Office. Census '96 Principal Socioeconomic Results. Dublin: Government of Ireland, 1998. 